This item was submitted to Loughborough's Research Repository by the author.

Items in Figshare are protected by copyright, with all rights reserved, unless otherwise indicated.

\title{
Digital human modelling over four decades
}

PLEASE CITE THE PUBLISHED VERSION

http://dx.doi.org/10.1504/IJDH.2016.077408

\section{PUBLISHER}

(C) InterScience

\section{VERSION}

AM (Accepted Manuscript)

\section{PUBLISHER STATEMENT}

This work is made available according to the conditions of the Creative Commons Attribution-NonCommercialNoDerivatives 4.0 International (CC BY-NC-ND 4.0) licence. Full details of this licence are available at: https://creativecommons.org/licenses/by-nc-nd/4.0/

\section{LICENCE}

CC BY-NC-ND 4.0

\section{REPOSITORY RECORD}

Case, Keith, Russell Marshall, and Steve Summerskill. 2019. "Digital Human Modelling over Four Decades". figshare. https://hdl.handle.net/2134/20654. 


\title{
Digital Human Modelling over Four Decades
}

\section{Keith Case}

Mechanical and Manufacturing Engineering, Loughborough University, Leicestershire, LE11 3TU, United Kingdom

K.Case@lboro.ac.uk

\section{Russell Marshall}

Loughborough Design School, Loughborough University, Leicestershire, LE11 3TU, United Kingdom

R.Marshall@lboro.ac.uk

\section{Steve Summerskill}

Loughborough Design School, Loughborough University, Leicestershire, LE11 3TU, United Kingdom

\section{S.J.Summerskill2@lboro.ac.uk}

\begin{abstract}
:
This paper aims to provide a retrospective of the use of a digital human modelling tool (SAMMIE) that was perhaps the first usable tool and is still active today. Relationships between digital human modelling and inclusive design, engineering design and ergonomics practice are discussed using examples from design studies using SAMMIE and government-funded research. Important issues such as accuracy of representation and handling multivariate rather than univariate evaluations are discussed together with methods of use in terms of defining end product users and tasks. Consideration is given to the use of the digital human modelling approach by non-ergonomists particularly with respect to understanding of the impact of human variability, jurisdiction and communication issues.
\end{abstract}

Keywords: Digital human modelling; SAMMIE; Inclusive design.

\section{Introduction}

The objective of this paper is to provide a retrospective of the use of a digital human modelling tool over a period that is approaching half a century. Rather than providing detailed explanations and descriptions of the modelling techniques which can be widely found elsewhere, the 


\section{Digital Human Modelling over Four Decades}

intention is to explore the relationships with inclusive design, engineering design and ergonomics practice. Much of this draws on design studies and government-funded research in inclusive design. The historical material is taken from three articles that have not been widely available (Porter, Case and Freer; 1996, Porter et al., 2003; Porter et al., 2009).

SAMMIE (System for Aiding Man Machine Interaction Evaluation) is a digital human modelling system that has been in development and use for over 40 years. Three-dimensional geometric representations of working environments and specific equipment can be built and evaluated using a human model that is a 3D representation of the human body with articulation at all major body joints. Data arising from very early studies are used to constrain joint movements (Barter et al., 1957) and body shape (Sheldon, 1940) and anthropometry can be varied to represent the relevant national or occupational populations. The modeller is intended for use in the very early stages of the design process, potentially saving costly design changes, to test the suitability of workplaces and workstations for the appropriate user populations.

Initially digital human modelling as it is now known was universally known as 'man modelling'. This may seem strange but it was really a shorthand for (hu)man modelling and of course the ergonomists involved were probably very much more aware of gender issues in design than were the general public. SAMMIE, the digital human modelling system, was initially developed at Nottingham University by two PhD students starting in 1968 (Evershed, 1970; Hughes, 1972). The New Scientist cover of May 1970 illustrates the early 'Ned Kelly' look - the crude gender differentiation of the passenger was the work of the editors (Figure 1). The strap-line 'Computer ergonomics fits man to machine' should make all ergonomists shudder, and again was the work of the editors. The early work was as notable for its innovative computer graphics as much as the ergonomics, and such was the scarcity of graphics devices that the students travelled over one hundred miles to the National Physical Laboratory in Surrey each weekend where they took over the laboratory's entire computer power. In the early 1970s the researchers spent two evenings a week using the mainframe computer at Warwick University (a 0.064 megabyte (!) Elliott computer) using paper tape and later, punched cards for programming.

There were several other modelling systems in the initial stages of development in the early 1970s. Kroemer (1973) surveyed the field and concluded that there were two distinct classes of man model. 'External biodynamic', briefly described in Von Gierke (1971), and considered to be outside the scope of the models described here. Kroemer's second 


\section{Digital Human Modelling over Four Decades}

category was models of the 'internal' type, where the important features are the anthropometry, kinematics, dynamics and energy capabilities of the body. The objectives of the models vary from the very specific work study application of MTM Man (Kilpatrick (1970)), to the more general approach of COMBIMAN (Kroemer (1973)) and BOEMAN (Ryan 1971) where workplace and task design is studied in the context of human factors. BOEMAN was developed by the Boeing Company for the Joint Army-Navy Aircraft Instrumentation Research Program (JANAIR) to assist in the evaluation of the cockpit design of military aircraft. The work was later transferred to the Aerospace Medical Research Laboratories of the USAF where it became known as COMBIMAN (Kroemer, 1973). MTM Man, developed at the University of Michigan by Kilpatrick (1970), had the prime aim of assisting workplace design with respect to the methods and times taken for tasks performed. (MTM-Methods-Time Measurements is the name given to a pre-determined motion time system). The biomechanical model developed at the University of Michigan by Chaffin (1969) was primarily concerned with assessing whether a task is within an operator's physical capabilities. CYBERMAN was developed by the Chrysler Corporation for automotive packaging (Waterman and Washburn, 1978). Subsequent reviews by Dooley (1982) and Porter, Case and Bonney (1990) review these models and others of the era.

The use of DHM has become diversified and several varieties are available. Some have been integrated into mainstream computer aided design systems so that Badler's long-standing work on JACK (Badler et al, 1985) is available as part of Siemens NX system (Siemens, 2015) and RAMSIS, widely used by the German automobile industry is integrated with CATIA (Human Solutions, 2015). Considerable advances have been made in increasing functionality in systems such as Santos (Yang et al, 2005) and IMMA (Hanson et al, 2014, Bertilsson et al, 2011). Realism, particularly in respect of body shape and dynamic movement, has been pursued by some, most notably the Thalmanns (Thalmann and Thalmann, 2012). Bubb and Fritzsche (2009) provide a useful review of recent and past developments. 


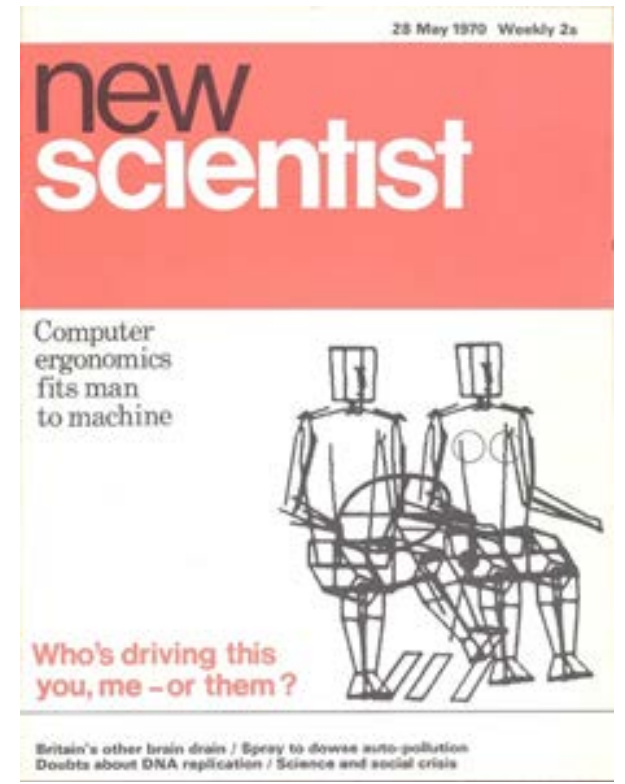

Figure 1 Front cover of the New Scientist 28 May 1970 (reproduced with permission)

In the mid-1970s a major Science Research Council grant allowed the purchase of one of the first Prime minicomputers in the UK and this became an integral part of the beginnings of JANET (Joint Academic Network). By the late 1970s the SAMMIE software, whilst continuing to be developed, was being applied in both research and design studies.

SAMMIE has been based at Loughborough University since the 1980s, and over the years protocols have been developed for a variety of ergonomics assessments which have been applied to numerous research and industrial applications, with a strong emphasis on the validation of the virtual analysis by using physical mock-ups in the later stages of the design process. Design studies have been undertaken over the years with collaborators and clients including the Brussels Tram, the Eurofighter aircraft, Hong Kong airport Lantau Line, Rover Group, Fiat, Jaguar and Rolls Royce, and more recently, the Rail Safety and Standards Board (RSSB), NCR, the UK Government Department for Transport and Transport for London.

Inclusive Design (or Design for All or Universal Design) appears to have become a topic of interest about the turn of the millennium (Coleman and Lebbon, 1999; Newell and Gregor, 2000). It seems to have arisen, at least in part, from the HCI (Human Computer Interaction) community concerned with usability and was concerned with extending the usability 


\section{Digital Human Modelling over Four Decades}

of products to older people and those with disabilities. These ideas were of course not new to the world of ergonomics but suitable data on human capabilities and design methods were under-developed. Consequently another major advance in SAMMIE was the facility to represent the abilities of a range of older people and people with disabilities in terms of joint range of motion that was made possible by the EQUAL (Extending QUAlity Life) programme (a major research programme of the Engineering and Physical Sciences Research Council - EPSRC) (Gyi et al., 2004). EQUAL focused on activities of daily living whereas the subsequent AUNT-SUE Project (Accessibility and User Needs in Transport) which was part of the EPSRC's Sustainable Urban Environments Programme was concerned with urban transportation (Marshall et al., 2009). These projects expanded the potential of the SAMMIE system through a new version of the program called HADRIAN. This inclusive design tool was the first human modelling tool to combine individual datasets for people of a wide range of ages and abilities, describing their size, shape, strength, postures and coping strategies (both physical and emotional), together with a task analysis tool that allows for the automatic evaluation of concept designs (Figure 2). More recently this work has been extended into the industrial environment with consideration of the needs of older workers given the growing demographic issues (Hussain et al., 2013).

Further development of analysis tools has been performed to meet the needs of specific research and design projects. A prime example is the development of a projection tool which allows the volume of space that is visible to the driver of vehicles through both windows and mirrors to be visualised, allowing blind spots in driver's vision to be identified (Marshall et al., 2013). 


\section{Digital Human Modelling over Four Decades}

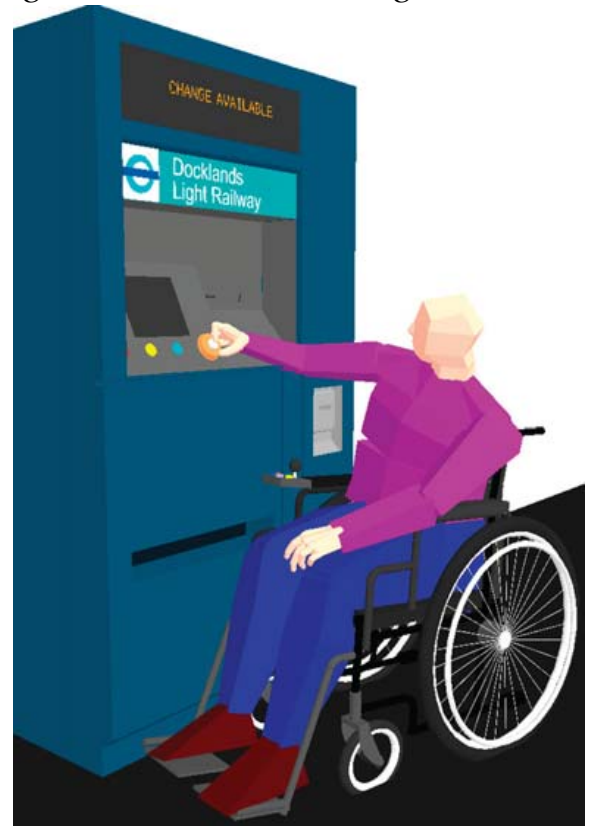

Figure 2 Ticket machine accessibility Docklands Light Railway

\section{Use of digital modelling systems}

Human modelling systems can be powerful tools for design teams as they enable predictions to be made of the percentage of future users of a proposed product or workplace who may have problems with clearances, reaching, seeing or the combination of all these requirements that may force unnatural and damaging postures. When problems are identified, it is possible for all of the design team to scrutinise the data and the assumptions used. The ergonomics problems with a proposed design can be presented visually thereby supporting efficient communication within the design team and solution orientated action.

SAMMIE has been used on a daily basis as a design tool (Case et al., 1990a; Case et al., 1990b; Porter, 1994; Porter et al., 1991; Porter et al., 1993, Summerskill et al, 2014). This section describes and discusses some of the more important issues that had to be dealt with during the development and application of digital human modelling. 


\section{Digital Human Modelling over Four Decades}

\subsection{Functionality of the system}

SAMMIE is a predictive tool to assess the postural constraints placed upon people when interacting with the designed physical environment. The basic functionality that is required is:

\subsubsection{Human modelling}

Human modelling is the 3D modelling of people of the selected gender, age, nationality and occupational groups. This is achieved using published anthropometric data for the population being examined. The current databases have several shortcomings, basically because they were established with little consideration for the needs of 3D human modelling systems.

Anthropometric data provide only a limited number of dimensions to define a 3D computer model. Should the human model remain as true as possible to the real data or should artistic license be granted to model more 'realistic' models? It is appreciated that highly lifelike models will attract attention and it is quite possible that this would be reflected in the increased usage of human modelling CAD systems, but at what cost? The danger is that the designer (be it an industrial designer, engineer or ergonomist) would come to believe the 'added' data and, for example, may feel confident that it is possible to utilise the human model for assessments where the true fidelity of the human model is inappropriate such as body-worn systems, seat cushion contours etc..

However, some research work focused on two areas where a more realistic representation of the human body has importance for ergonomics evaluation purposes. A detailed geometric model of the spine was developed for research into the effects of product design on spinal posture and its possible consequences in terms of discomfort or long term damage (Stepney et al., 1996). Secondly, in attempting to gain a better understanding of driver comfort and a more precise prediction of important design points such as the eye-point and H-point, it was realised that a more accurate representation was required for both the human flesh and the car seat. Figure 3 shows a flesh shape that was acquired from real subjects using a shadow scanning technique (Case, Xiao and Porter, 1995; Jones, et al., 1989). In recent years the acquisition of detailed flesh forms has become relatively common and accessible with the proliferation of 3D body scanning systems. These can now be used by DHM systems to provide more accurate and representative body shapes for virtual humans. However the issues still remain of how the body form captured from an 


\section{Digital Human Modelling over Four Decades}

individual can be manipulated to create generic templates for any body size that a designer may wish to model.

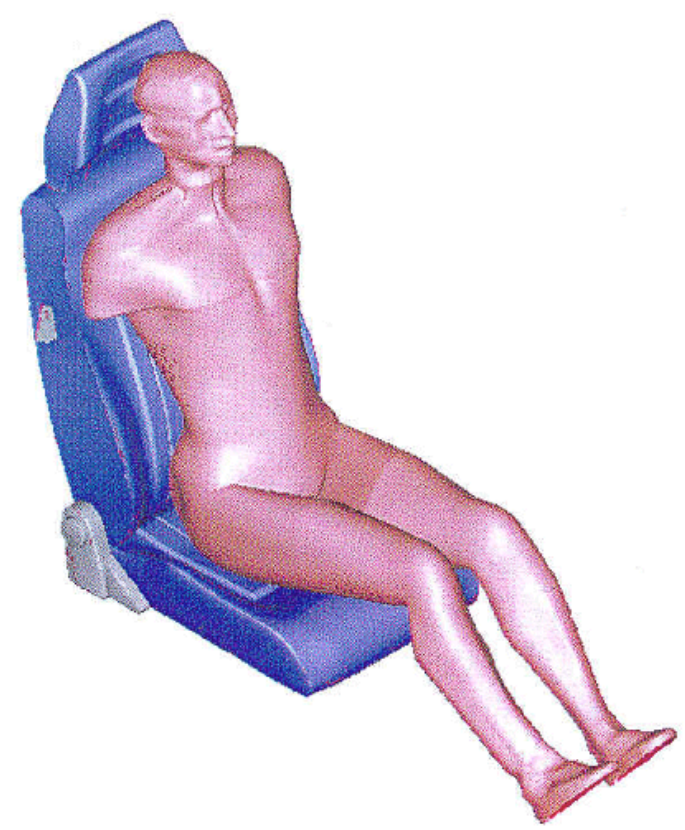

Figure 3 Shadow-scanned flesh representation

\subsubsection{Comfort angles}

To appropriately constrain a human model requires some form of knowledge base of comfort angles for the major joints of the body. Such data are widely available for application areas such as computer workstations and cars. However, closer examination often reveals disagreement in the literature or the recognition that the recommended postural angles are based only on theoretical analysis. For example, for many years it has been accepted that people using computers should adopt an identical posture to that taught to typists in the past, specifically sitting upright with angles around 90 degrees between the trunk and thigh and at the elbows, knees and ankles. However, a quick glance at any room full of people using computers shows that such a posture is rarely adopted. This begs the question "should we design for a posture that will only be rarely used?”

\subsubsection{Workstation modelling}

There is a need to model the proposed workstation in 3D together with the simulation of ranges of adjustment to be incorporated into the design. The 


\section{Digital Human Modelling over Four Decades}

ability to make iterative modifications to the design to achieve optimum compromises. Design is all about working within constraints, and sometimes challenging these constraints, to achieve the best compromises. The public's demand for better ergonomics in their homes, offices and lifestyle is continually increasing, as is the legislation to enforce it.

\subsubsection{Kinematic Interactions}

Kinematic interaction between the models of people and the workstation, specifically in terms of the issues of user fit, reach and vision should be available. The assessment will focus on whether or not the people modelled can work efficiently at the workstation and can adopt a 'comfortable' posture (i.e. within the ranges of joint angles considered acceptable).

\section{Design projects}

Any design project starts by asking a number of basic, but essential questions. Firstly there is a need to determine exactly who the intended users of a design will be, and whilst this seems like an obvious starting point, is often not at all clear in the client's mind. This forces the client to make important decisions about the acceptable accommodation range (e.g. 5th to 95th percentile or wider) and the user population in terms of nationality, gender and age groups at the earliest stage of design. For example in an evaluation of a helicopter development (see Figure 4) it was possible to demonstrate to the client that the existing aircraft chosen as a

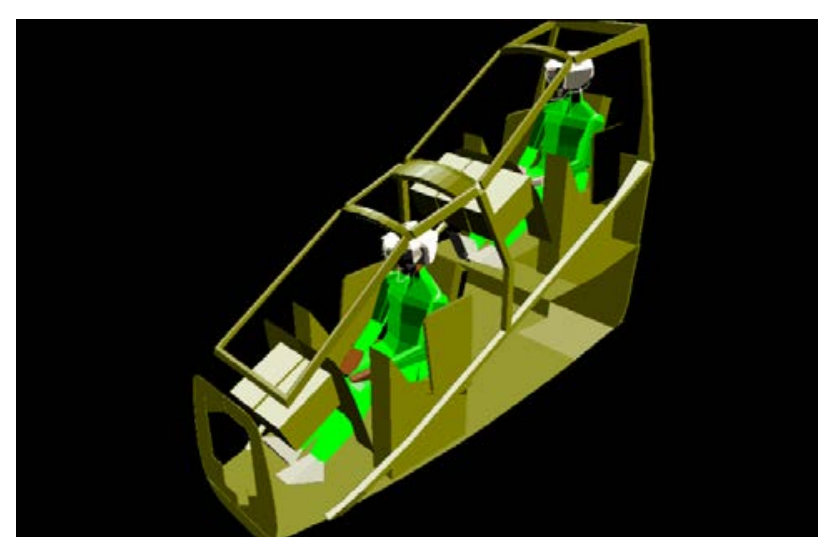

Figure 4 Concept helicopter design 


\section{Digital Human Modelling over Four Decades}

starting point, initially without particular regard to the users, was not capable of accommodating the population extremes (97.5th percentile Dutch male pilots and 25th percentile female pilots of other European nationalities) without structural changes so great as to warrant an almost completely new airframe.

The next step is to help the client to establish a clear definition of all the tasks the user is required to perform in order that they can be simulated in the evaluation. This helps to establish a specification for the workstation equipment and to set task priorities. This process often identifies conflicts between various task functions. For example, in the design of the Brussels Tram (see Figures 5 and 6) it was established that the driver had two equally important but conflicting tasks, namely driving the vehicle and selling tickets to passengers. A cab designed to allow ease of operation, optimum visibility and comfortable postures whilst driving was found to be severely compromised by the requirement to have the driver swivel around and sell tickets whilst remaining seated. Since DHM is a visual medium it was possible to clearly demonstrate the problem to the rest of the design team and together it was possible to look for solutions by quickly developing and investigating a variety of alternative seat movement mechanisms and rotation points in the SAMMIE model.

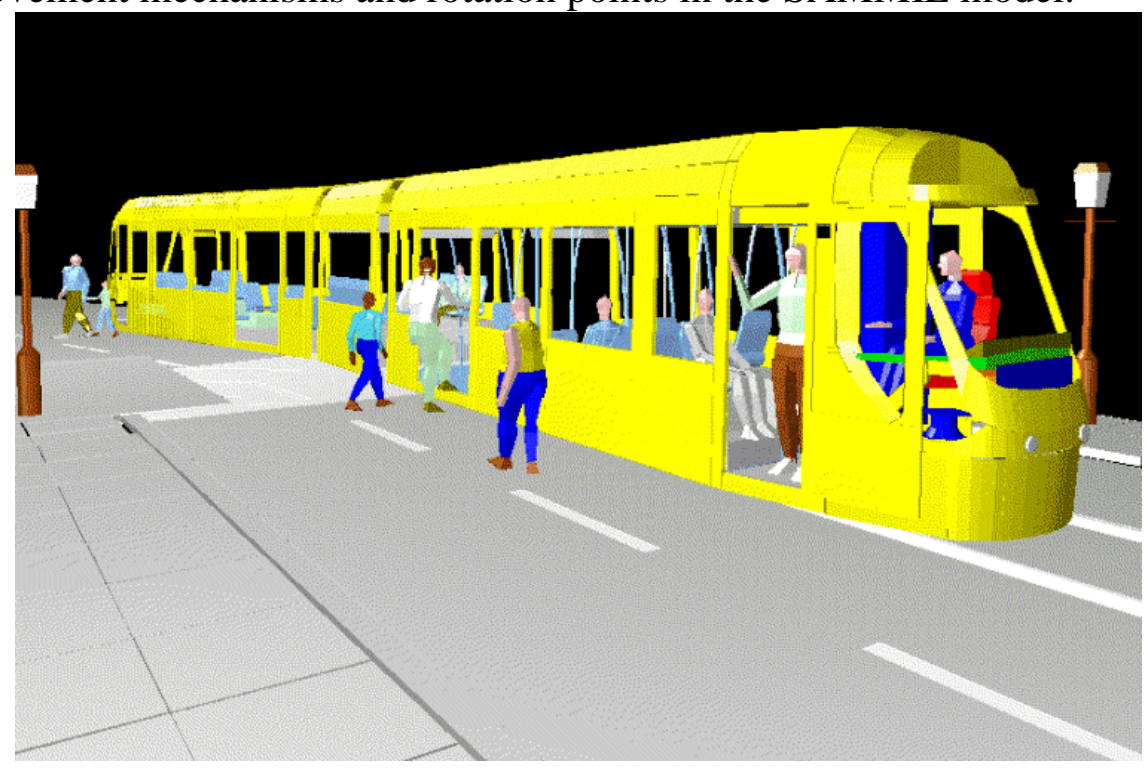

Figure 5 SAMMIE model of the Brussels Tram. 


\section{Digital Human Modelling over Four Decades}

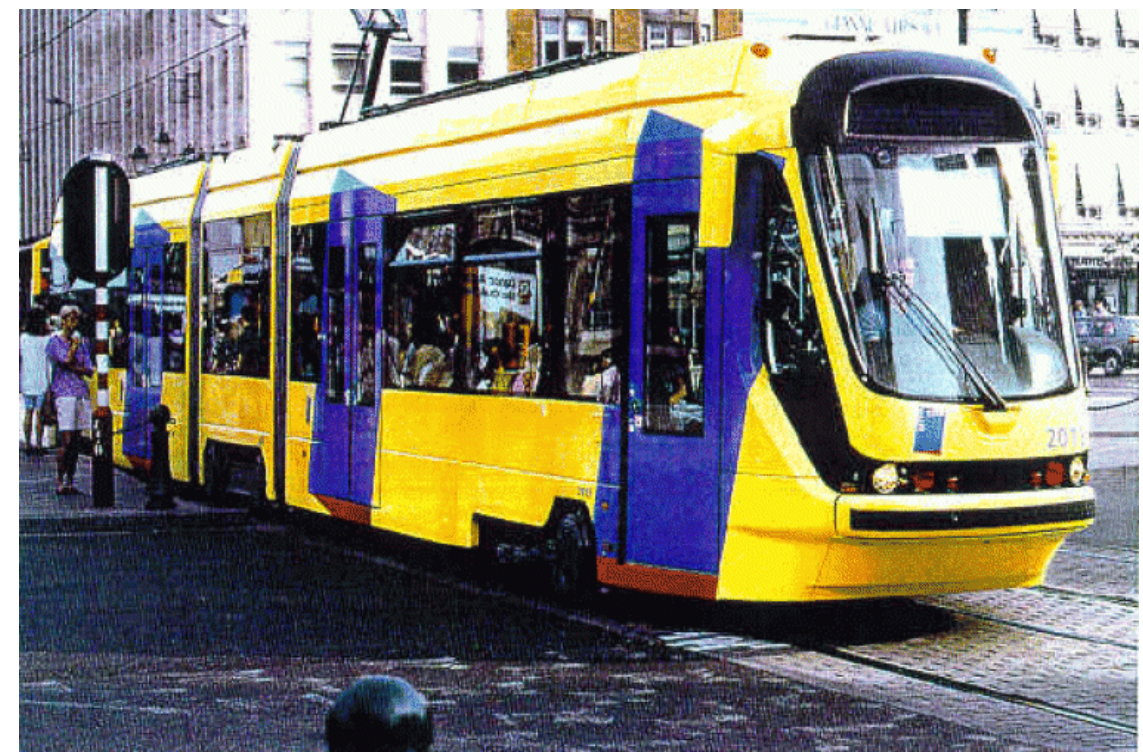

Figure 6 The Brussels 2000 Tram in service.

Another important consideration often overlooked is the working environment and its possible effects upon user task performance. A project examined control design for a military aircraft cockpit in which the control

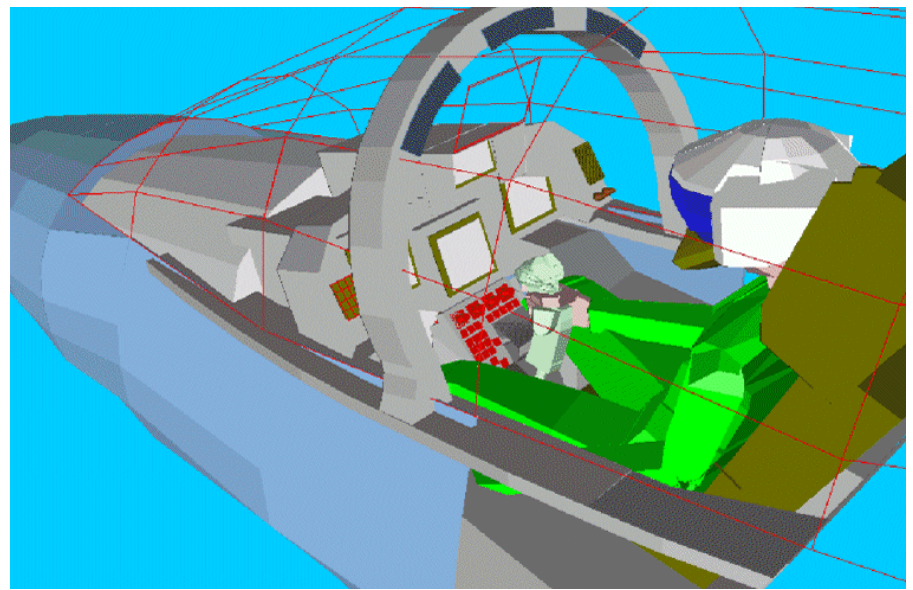

Figure 7 Reach to control stick in aircraft cockpit. The functional hand model was developed for use on this project.

would only be used when the aircraft was 'out of control' (see Figure 7). 


\section{Digital Human Modelling over Four Decades}

This posed several issues which had not been considered because the pilot had always expected to be 'in control'. In addition, the motion conditions under which this particular control might be used are so severe that the 'normal' usability criteria for acceptable reach and vision identified by the client were totally inappropriate.

Determining who the users are, what tasks they perform and under what conditions they are expected to work, is important in that it forces the client to make decisions that affect the usability of a workstation at the earliest possible stages of design, thereby ensuring the early input of ergonomics expertise. This is one of the major benefits of the use of digital human modelling. Other advantages include a reduction in project time scale, the ability to have a rapid iterative design process and improved communication within the design team. Because the analysis techniques are logical and objective in approach, all of the stakeholders in a project can easily visualise any design problems identified, question any assumptions made and have a direct involvement with the investigation of alternatives.

SAMMIE enables rapid and timely iteration. For example, development of the cab for the Lantau express train for Hong Kong's airport started from the designers' creation of a number of initial exterior forms (Figure 8). It was possible to build up a model of the cab structure and start to develop a suitable workstation before any engineering drawing or other CAD modelling was started. Importantly the client had several changes of mind regarding the external form which required major changes to the cab body. Structural changes could be made to the model as they arose and their effect on the workstation could be assessed immediately. Indeed the client later decided that the passenger emergency evacuation route had to be through the front of the train which effectively cut the cab into three. The implications of this on the driver's workstation could be evaluated and it was shown how this requirement might be accommodated with the minimum number of compromises, mostly by reducing the amount and size of equipment required by the driver in order to fit a usable workstation into the smaller space. The mock-up built from the SAMMIE design is shown in Figures 9 and 10. 


\section{Digital Human Modelling over Four Decades}

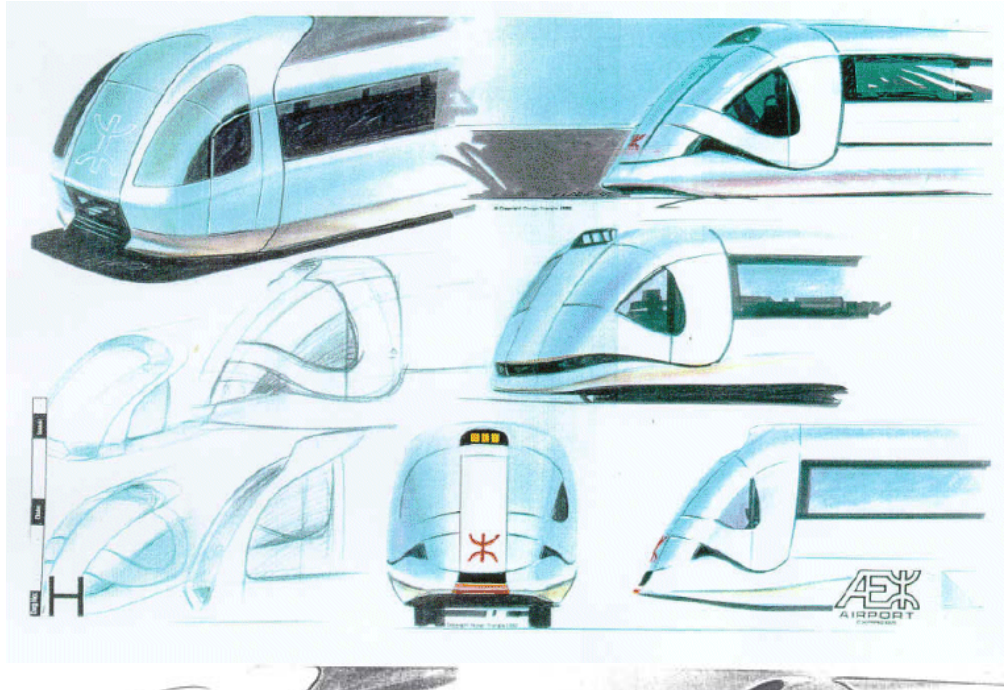

Figure 8 Artwork showing shoeing some of the exterior styling ideas for the Lantau Express Train for Hong Kong's new airport (Courtesy of Design Triangle, Cambridge, UK)

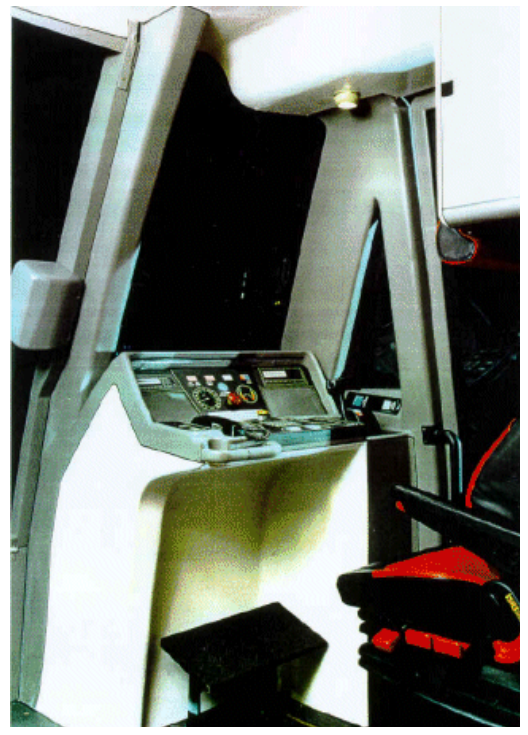

Figure 9 A mock-up of the Lantau Express driver's console built from the SAMMIE model. 


\section{Digital Human Modelling over Four Decades}

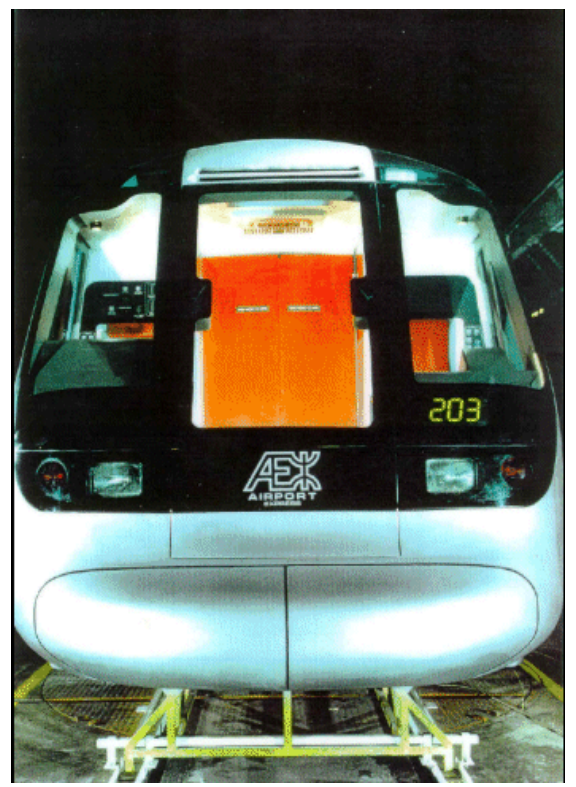

Figure 10 An exterior view of the mock-up of the Lantau Express train.

\section{Training issues}

As has been highlighted, one of the significant advantages offered by digital human modelling is timely ergonomics input. However, it is increasingly common for DHM systems to be used by non-ergonomists. Due to increased usability, fidelity and capability of DHM tools there is a growing perception that the tool can provide the required ergonomics expertise and this can be exploited by other disciplines in lieu of formal ergonomics or human factors input. Whilst the tools may be highly capable, significant understanding is still required in utilising DHM in both the design and implementation of an evaluation and in the interpretation of results. One of the most important features of an ergonomist is not just their data and methods but the philosophy or change in viewpoint that they can bring to the design team. This person-centred viewpoint takes time to mature and it needs to be reinforced with the study of several related areas such as the physiological, psychological, organisational and environmental factors that are present in any given design scenario. Some of the more 


\section{Digital Human Modelling over Four Decades}

important differences, from our own experience, in the approach taken by engineers, designers and ergonomists are listed below:

\subsection{Variability}

The engineering approach is to design out variability and as a consequence, the statistical mean of an attribute of the product, be it a dimension, weight, strength etc., is a very good predictor of all products being produced at that time. The statistical mean is also the best predictor for people variables as well, although the variability is so great that it is of considerably less interest for design purposes. Put crudely, designing for clearances, reach and strength using the statistical mean for the appropriate variable will result in up to half of the intended population being 'designed out'. It is critical that human variability is recognised and embraced by designers.

\subsection{Jurisdiction and communication}

Designers are particularly adept in communicating their ideas as they rely chiefly upon the visual image. As the major influences for a design are achieved at the concept stage then such people also have a wide jurisdiction of influence. For example, their sketches of handles and seats may be stylish and refer to ergonomics but in reality pay scant attention to ergonomics principles; however, they often form the basis for the production specification.

Engineers are also able to communicate effectively with each other through engineering drawings and technical analyses. Ergonomists typically contribute to design by providing data concerning human characteristics and by providing evaluative data concerning issues such as discomfort, usability and safety. These inputs do not directly influence the design unless the solution can be sketched or dimensioned accurately. Consequently, the ergonomist has traditionally had to rely upon the support of the other team members in order to incorporate the ergonomics specification.

Ergonomists, in our experience at least, are rarely asked to comment upon styling or engineering issues although designers and engineers are more than happy to deal with the ergonomics issues. Presumably, this confidence is based upon the assumption that introspection and the consideration of one's own problems and feelings towards a proposed design will be typical of most other people.

Human modelling CAD systems can help enormously in getting the ergonomics issues considered at the concept stage of design. This is 


\section{Digital Human Modelling over Four Decades}

because dimensionally accurate perspective views can be presented of both the design and the users. This gives the ergonomist the opportunity to be pro-active and to support the other design team members using communication methods that are completely natural for them.

\subsection{User behaviour}

There is a concern that the use of human modelling systems by nonergonomists will lead to standardised procedures being developed taking little account of differences in user behaviour. It does not necessarily follow that people will hold dangerous pieces of equipment by the handle as intended. Virtual people may do as they are instructed, but real people, particularly when poorly trained, fatigued, under stress, working to a tight schedule and so on, must not be expected to be so disciplined. This level of understanding and healthy scepticism of predictive tools can be easily overlooked by designers and engineers who not familiar with the subtleties of human behaviour and the limitations of the available data.

\section{Validity}

Experience has shown that the geometric evaluations of fit, reach and vision are acceptably accurate through many industrial projects which have successfully undergone the transition from computer-based prototype to full-size mock-up and then manufacture.

However, whenever possible the aim is to combine the use of DHM with the more traditional ergonomics methods. We have always advocated that human modelling systems should not replace user trials with full size mock-ups, unless the design or the design modifications are so simple as to not warrant concern. In-depth user trials can reveal problems with so many more issues including long term discomfort, effects of fatigue, negative transfer of training, error rate, performance and even the acceptance of the product. Many designers, engineers and ergonomists are expectantly waiting for the all-singing, all-dancing human modelling system to appear which can remove the need for physical prototypes. The likelihood of such a system being developed either in the near or distant future seems remote. 


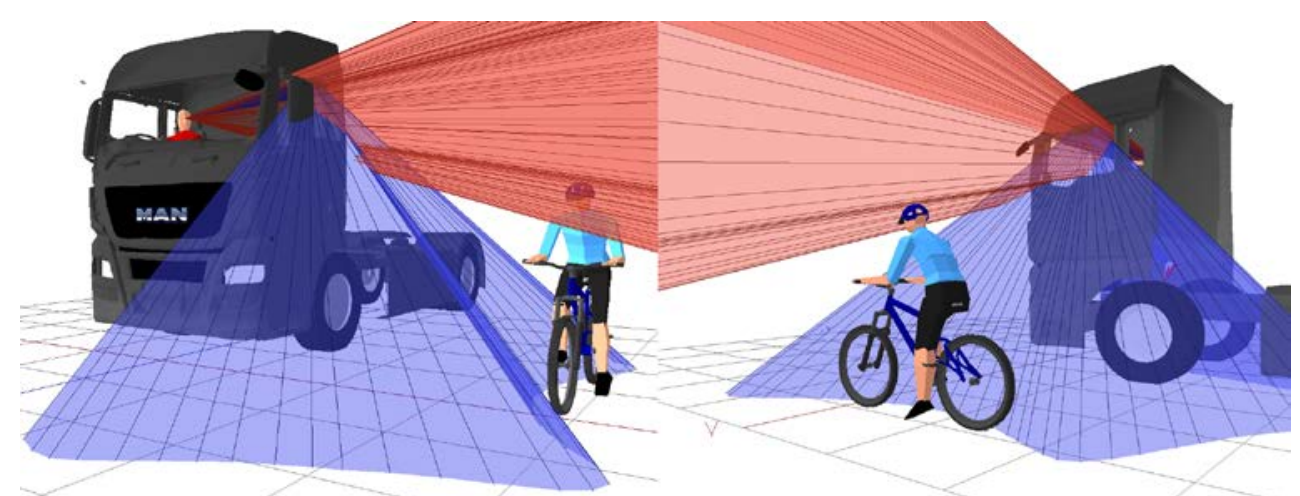

Figure 11 The use of the SAMMIE mirror and window aperture projection technique in the identification of a key Blind Spot in the vision of HGV drivers

There have been examples of the use of DHM where the virtual testing of a situation is superior to the real world testing. An example of this is the development of tools and techniques that allow the visualisation of blind spots in the vision of heavy goods vehicles (HGVs) drivers. The UK Government Department for Transport commissioned a study to quantify the size and location of blind spots around the cabs of HGVs due to the accident data that is collected in the UK indicating that a disproportionate number of accidents were occurring between HGVs, vulnerable road users and other vehicles (Cook et al., 2011). A tool was developed that allows the volume of space that is visible to the driver through windows and mirrors to be visualised. The combined projection of all windows and mirrors that is possible with the projection technique allows blind spots to be identified. The modelling and visualisation of the complex three dimensional volumes of visible space that are produced by a range of mirrors with radius of curvature in the region of $300 \mathrm{~mm}$, is not possible in a real world testing context. The innovative work identified a key blind spot between the volume of space visible through a 'look down mirror' (Class $\mathrm{V}$ mirror) and the volume of space through the passenger window, as illustrated in Figure 11. This work led directly to the revision of UNECE Regulation 46 (UNECE, 2015), with the revised standard requiring the blind spot to be removed through the redesign of the Class $\mathrm{V}$ mirror. All HGVs of a particular category sold in Europe will need to meet this revised standard from July of 2015.

DHM uses CAD techniques both as a tool for ergonomics analyses and as a medium for communication. For the purposes of many ergonomics analyses the requirements on the fidelity of the CAD data are modest. In modern systems the engineering level data that is commonly available in CAD tools is often unnecessary. However the power of DHM as a 


\section{Digital Human Modelling over Four Decades}

visualisation tool, and the confidence that can be inspired or eroded due to the appearance of a model is not insignificant. It is often the case that a particular issue has to be communicated to those unfamiliar with the technicalities. In such situations DHM tools provide an accessible means to highlight the impact on users, workers or other people of a given design due to the empathy conveyed through the use of a virtual human. Equally care needs to be taken with this capability as it is all too easy to provide confidence that ergonomics issues have been addressed and resolved through an assessment with a limited number of unrepresentative human models in unrepresentative postures where no feedback has been gained in the more subjective elements such as comfort for which DHM has limited capability.

The point has been made earlier in this paper that designers and engineers often deal with the ergonomics issues themselves. In the traditional design process, before CAD systems became so widespread, there was a need to make full-size mock-ups periodically for a variety of reasons, including legislative checks, visualisation and determining the appropriate method of manufacture. Many ergonomics issues would have been noticed at this stage as the various people involved interacted directly with the mock-up. The ubiquity of CAD has changed the design process from an ergonomics viewpoint as full-size mock-ups are now made less frequently and, when they are made, it is at a later stage in the product's development. As a consequence, there is a real concern that even some of the more basic ergonomics issues will no longer be self-evident to the design team unless human modelling systems are also incorporated into the design process. However even more recent development may have the potential to reintroduce some of the inherent human input opportunities into the development process. The increasing proliferation of 3D printing technology has seen a growth in the production of prototype designs directly from CAD data. These prototypes can be of very high fidelity and are relatively quick and cost effective to produce. Designers are recognising the value in producing these $3 \mathrm{D}$ printed models to assess form, functionality and other design issues, in addition they are provide an ideal opportunity to assess user interaction and provide a means for ergonomics issues to be revealed.

\section{Representativeness}

The ability for a virtual human to be modelled that represents the characteristics of a real person have been discussed. Many of these characteristics such as body size and body shape are well understood. 


\section{Digital Human Modelling over Four Decades}

However they also tend to be characteristics for which there are robust data available and that can be simplified into statistical models or other representations that can lose some of the richness of human variability. Even within these relatively well understood areas, there are complexities (Porter \& Porter, 2001). When considering body size in the form of anthropometry, it is not uncommon to assess the limits of accommodation e.g. $5^{\text {th }}$ and $95 \%$ iles. However, the meaning of these terms is by no means straightforward. Designing to accommodate a $5^{\text {th }} \%$ ile female could result in the smallest $5 \%$ of the female population being excluded. This would also inherently be affected by the nationality of the female population being considered. Furthermore, the exclusion is attributable to a single dimension e.g. stature. When multiple dimensions are considered, e.g. stature and sitting height, in what is termed multivariate analyses (Porter, 2001; Porter et al, 2002), the 5\% excluded are not the same for each, and so the exclusion will be greater than $5 \%$. Once the number of design variable reaches seven or more a $5^{\text {th }}$ to $95^{\text {th }} \%$ ile approach could be excluding between a third and half of the intended user population (Roebuck et al., 1975; Herman Miller, 2015). Designing for $5^{\text {th }}$ to $95^{\text {th }}$ \%ile is a very common approach and almost a de-facto standard in many industries. Yet how many designers or engineers have any concept of what $5 \%$ of a population actually means in terms of acceptance, usability or safety in the use of a product or workstation? Equally, the common interpretation of the terminology $5^{\text {th }}$ or $95^{\text {th }} \%$ ile refers to a so called univariate human model; a virtual human for which all body dimensions are the same percentile. In real people this univariate body proportionality is very unusual and as such univariate manikins are actually not at all representative of the populations they have been very specifically created

to represent. Amongst ergonomists and in the DHM community these complexities are well understood and research has been done to try to identify boundary manikins (Brolin et al., 2012), or produce manikin families (Bittner 2000; Högberg, Hanson and Case, 2003) that are more representative of the national populations that designers would wish to use to assess their products.

Even within the more well understood complexities of representing user populations there are significant limitations. Almost all data used to drive the construction of human models has been collected from adults 1865years who have no disabilities. Thus the human models created will have limited ability to represent the specific characteristics of either the global ageing population, or those with disabilities.

The arguments for a Design for All or Inclusive Design approach to product, environment or service design are clear and well understood. In 


\section{Digital Human Modelling over Four Decades}

order to address the underlying issues it is vitally important that designers are educated, informed and supported in the principles of Design for All, with appropriate and applicable data, and with the tools and techniques to employ this data in their design activity.

Research funded by the Engineering and Physical Research Council in the UK resulted in the development of HADRIAN. HADRIAN (Human Athropometric Data Requirements Investigation and ANalysis) is a partner tool to SAMMIE. The tool provides a sample database of 100 individuals across a broad spectrum of ages and abilities together with a task analysis tool. The HADRIAN system allows the designer to assess their designs against the population in the database to determine the percentage who are effectively 'designed out'.

The system has been developed to build empathy with the target population. In addition, the system provides a relatively simple, yet powerful, method of obtaining a form of user feedback and insight normally only attainable through expensive prototype mock-ups and user trials. This feedback is also provided at a much earlier stage of the design process.

In order to address these issues HADRIAN provides a computer database of 'individuals' has been developed so that multivariate analysis can be conducted on a wide range of real people of all ages, abilities, shapes and sizes. As opposed to tables of percentiles for each body dimension the database preserves the information for each individual as a complete dataset (Figure 12).

The database comprises 103 individuals, including a large proportion who are older and/or disabled who collectively form a virtual user group that can be used to assess products and environments. HADRIAN's database features allow the designer to investigate the stored data on the individuals, not only for the purposes of determining a suitable user group for task analysis but also to allow them to become more familiar with the users. In addition to the range of anthropometric and mobility data, HADRIAN stores extremely rich and relevant design data on the individuals, including pictures, video of task behaviours and capabilities so that the designer may gain some empathy with the user they are trying to design for. 


\section{Digital Human Modelling over Four Decades}

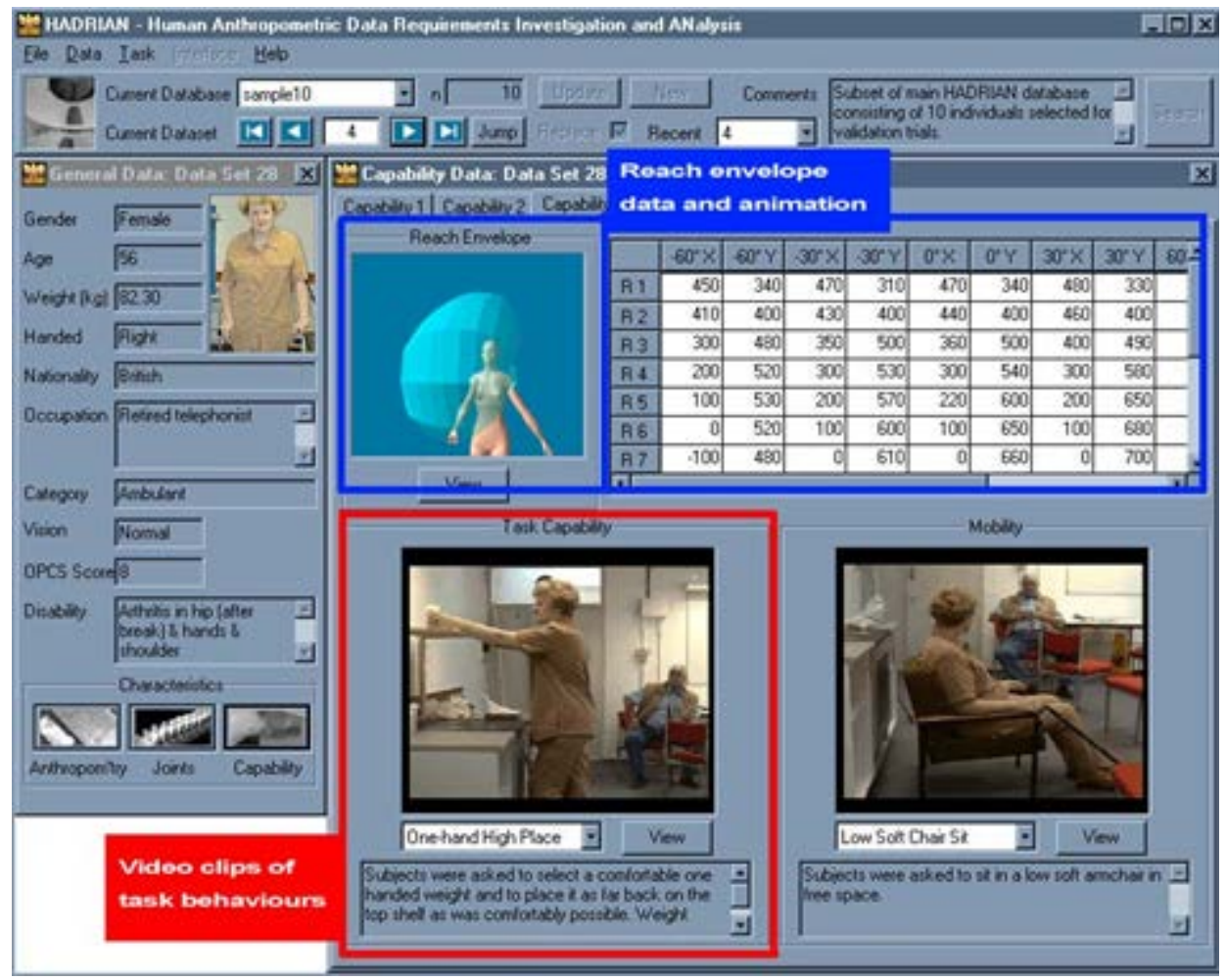

Figure 12 The HADRIAN system showing one part of the capability data for an individual.

HADRIAN also provides a task based analysis tool. The virtual user group can be used to assess the accommodation of a design in a similar manner to a real user trial. The user of the system can define the requirements for the analysis through the description of the task they wish the virtual users to perform. The individuals in the database are then

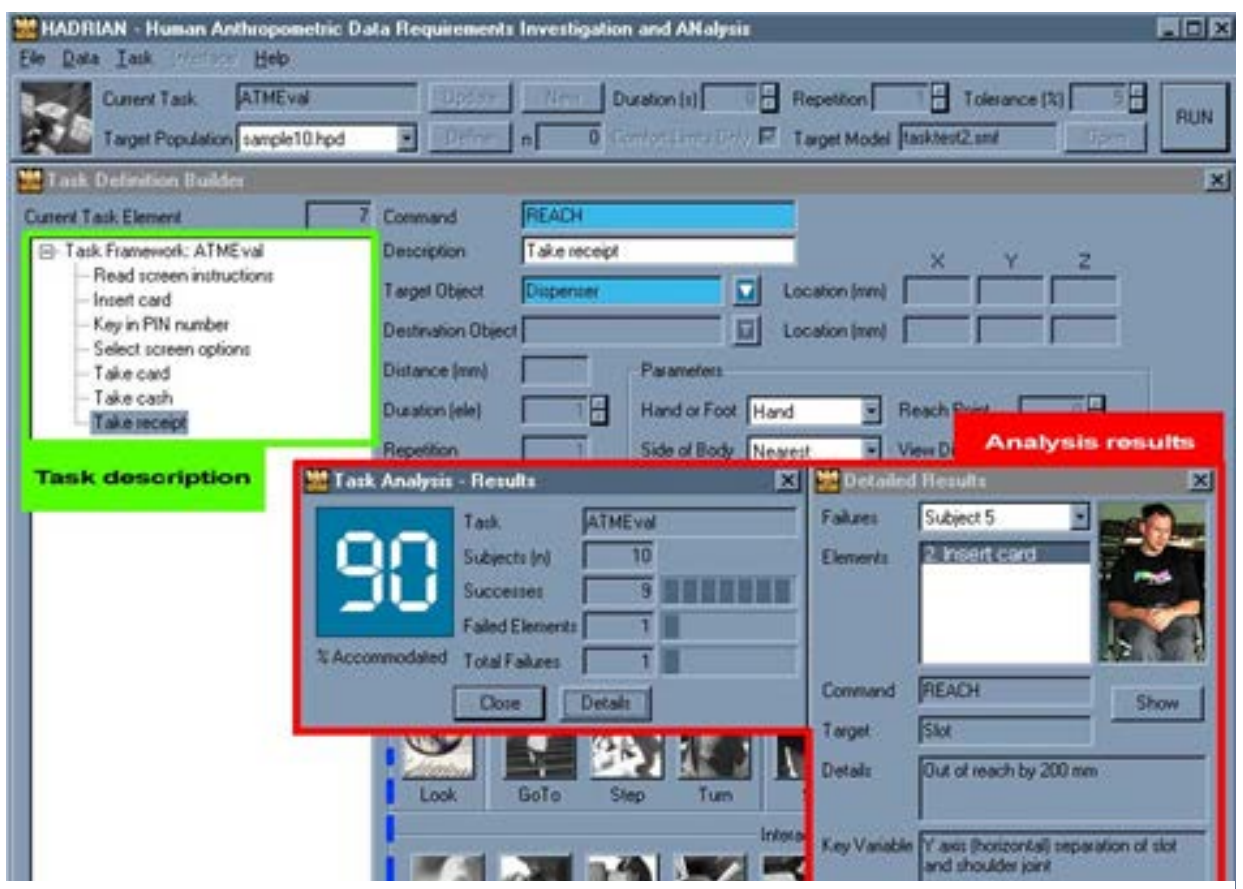

Figure 13 HADRIAN system showing task analysis interface and results of the ATM trial. 


\section{Digital Human Modelling over Four Decades}

modelled and attempt to perform the task as defined. Using coded behavioural data embedded in each individual together with an overarching logic framework HADRIAN attempts to assess the ability for each virtual user to complete the task in a manner representative of their actual behaviour. The result is a measure of inclusivity / exclusion (Figure 13) and details on who has been excluded. This provides a useful metric for the design team to look to maximise the inclusivity of their design, but also provides a degree of empathy with the user group. Designs are no longer excluding a nameless and faceless $5 \%$ of the population but actual 'real' people and forcing them to consider important questions about the appropriateness of such an approach.

\section{Discussion}

Digital human modelling has, of necessity, developed alongside the computer technologies that support it. At the outset computer hardware was rudimentary in comparison with today's and availability of suitable application graphics software was almost non-existent. Early developers were making general advances in fields such as computer graphics and solid modelling which, whilst this eventually contributed to current computer aided design systems, was at the time a burden that slowed the development of the human modelling application.

Digital human models of the type that provide a manikin for evaluation assistance in what might be called physical ergonomics have been shown to have been useful for many years - principally in the areas of reach, fit, postural assessment and vision. However, the integration of this technology within the engineering design function is not satisfactory and efforts are ongoing to improve this situation. As well as software integration this will also require ergonomists to work with design engineers in much the same way as for example stress analysts do at present.

The provision of ever more realistic and more capable models should be viewed in the light of the potential limitations in the application methodology. As modellers become more capable there is an even greater need for users to have a proper understanding of their limitations in the wider context of ergonomics. DHM users need to have an understanding of human variability and its influence on design, the implications of varied and perhaps unpredictable human behaviour, the extent to which the modellers are, or are not, representative of a particular capability and the consequences of considering design in a univariate way. There is also a need to recognise more strongly that as well as representing the human 


\section{Digital Human Modelling over Four Decades}

and the workplace there is a need to describe the tasks to be undertaken. HADRIAN goes some way in representing human variability in a multivariate form by the use of a database of very diverse individuals (rather than a statistical representation of a population) and evaluating accommodation through a task-driven virtual user trial approach. This methodology also supports the aims of inclusive design where there is an even more diverse population with an emphasis on older people and those with disabilities.

Beyond the physical ergonomics there are many possibilities for developing DHM to represent aspects such as the cognitive, behavioural and emotional characteristics of humans. Work has begun in these areas but there is a very considerable way to go before effective design tools are produced.

\section{Conclusion}

This paper has attempted to provide a retrospective over the early years of digital human modelling, an indication of the current state and a few pointers to the future. No attempt has been made to provide a detailed description of the technology, but aspects of the use of DHM in product design have been illustrated with example applications.

\section{Acknowledgements}

The late Professor Mark Porter made very significant contributions to the work described in this paper, as did Professor Maurice Bonney and Martin Freer. The funding by the Science Research Council and its successor the Engineering and Physical Science Research Council is also gratefully acknowledged.

\section{References}

Badler, N. I., Korein, J. D., Kopein, J. U., Radack, G. M. and Brotman, L. S. (1985) 'Positioning and animating human figures in a task-oriented environment', The Visual Computer, Vol. 1, No. 4, pp.212-220.

Barter J.T. Emmanuel I. and Truett B. (1957) A Statistical Evaluation of Joint Range Data, WADC Technical Note 57-311. Wright-Patterson Air Force Base, Ohio.

Bertilsson, E., Hanson, L., Högberg, D. and Rhen, I.M. (2011) 'Creation of the IMMA manikin with consideration of anthropometric diversity', 


\section{Digital Human Modelling over Four Decades}

Proceedings of the 21st International Conference on Production Research (ICPR), Stuttgart, Germany, pp.416-420.

Bittner, A.C., (2000) 'A-CADRE: Advanced family of manikins for workstation design', Proceedings of the IEA 2000 / IHFES 2000 Congress. Human Factors and Ergonomics Society, Santa Monica, CA, pp.774-777.

Brolin, E., Hogberg, D. and Hanson, L. (2012) 'Using experimental design to define boundary manikins’, Work, Vol. 41, No. 1, pp.4598-4605.

Bubb, H., and F. Fritzsche. (2009) 'A scientific perspective of digital human models: Past, present, and future.' In V. G. Duffy (Ed.), Handbook of Digital Human Modeling, Vol. 3, Boca Raton, FL: CRC Press, Taylor \& Francis Group, pp.1-30.

Case, K., Bonney, M.C., Porter, J.M. and Freer, M.T. (1990a) 'Applications of the SAMMIE CAD system in workplace design', in Haslegrave, C.M. et al (Eds.), Work Design in Practice, Taylor \& Francis, London, pp.119-127.

Case, K., Porter, J.M. and Bonney, M.C. (1990b) SAMMIE: 'A man and workplace modelling system', in Karwowski, W. et al (Eds.), Computer-Aided Ergonomics, Taylor \& Francis, London, pp.31-56.

Case, K., Xiao, D-C. and Porter, J.M. (1995) 'Car seat and occupant modelling using CAD', in Stockton, D. et al (Eds.), Advances in Manufacturing Technology IX, Taylor and Francis, London, pp.149153.

Chaffin, D.B. (1969) 'A computerized biomechanical model Development of and use in studying gross body actions', Journal of Biomechanics, Vol. 2, pp.429-441.

Coleman, R. and Lebbon, C. (1999) Inclusive design, Helen Hamlyn Research Centre, Royal College of Art, London, UK.

Cook, S., Summerskill, S., Marshall. R., Richardson, J.H., Lawton, C., Grant, R., Bayer, S.H., Lenard, J. and Clemo, K. (2011) The development of improvements to drivers' direct and indirect vision from vehicles - phase 2, Report for Department for Transport DfT, TTS Project Ref: S0906 / V8. Loughborough: Loughborough University.

Dooley, M. (1982) 'Anthropometric modelling programmes - a survey', IEEE Computer Graphics and Applications, Vol. 2, No. 2, pp.17-25. 


\section{Digital Human Modelling over Four Decades}

Evershed, D. C. (1970) A Computer Model of Man for Workspace Assessment. Unpublished $\mathrm{PhD}$ Thesis, University of Nottingham University, UK.

Gyi, D. E., Sims, R. E., Porter, J. M., Marshall, R. and Case, K. (2004) 'Representing older and disabled people in virtual user trials: data collection methods', Applied Ergonomics, Vol. 35, pp.443-451.

Hanson, L., Högberg, D., Carlson, J. S., Bohlin, R., Brolin, E., Delfs, N. and Rhen, I. M. (2014) 'IMMA-intelligently moving manikins in automotive applications', Proceeding of ISHS 2014, Third International Summit on Human Simulation.

Herman Miller. (2015) The anthropometrics of fit: Ergonomic criteria for the design of the Aeron chair, http://www.hermanmiller.com/research/solutionessays/anthropometrics-of-fit.html. (Accessed 17 July 2015).

Högberg, D., Hanson, L. and Case, K. (2003) 'Computer manikin family usage in human accommodation', in Rafnsdóttir, G.L. et al (Eds.), Mind and Body in a Technological World, the Proceedings of the Nordic Ergonomics Society Thirty-fifth Annual Conference, NES 2003, Reykavik, Iceland, pp. 184-188.

Hughes, B. J. (1972) A computer graphics approach to modelling and evaluating workspaces. Unpublished $\mathrm{PhD}$ Thesis, University of Nottingham, UK.

Human Solutions (2015) www.human-solutions.com/ (accessed 30 November 2015).

Hussain, A., Case, K., Marshall, R. and Summerskill, S. (2013) 'An inclusive design method for addressing human variability and work performance issues, International Journal of Engineering and Technology Innovation, Vol. 3, No. 3, pp.144-155.

Jones, P.R.M., West, G.M., Harris, D.H. and Read, J.B. (1989) 'The Loughborough anthropometric shadow scanner, Endeavour, New Series, Vol. 13, No. 4, pp.162-168.

Kilpatrick, K. E. (1970) A model for the design of manual work stations, Unpublished PhD Thesis, University of Michigan, USA.

Kroemer, K.H.E. COMBIMAN. (1973) Computerized biomechanical man-model, Wright-Patterson Air Force Base, Ohio. Report No.

AMRL-TR-72-16. 


\section{Digital Human Modelling over Four Decades}

Marshall, R., Case, K., Oliver, R.E. Gyi, D.E., and Porter J.M. (2002a) 'A task based "design for all" support tool', Journal of Robotics and Computer Integrated Manufacturing, 18(3-4), pp.297-303.

Marshall, R., Case, K., Gyi, D.E., Oliver, R.E. and Porter J.M. (2002b) 'HADRIAN: An integrated design ergonomics analysis tool', Proceedings of the International Annual Occupational Ergonomics \& Safety Conference, Toronto, Canada, pp.1-6.

Marshall, R., Porter, J. M., Sims, R. E., Summerskill, S. J., Gyi, D. E. and Case, K. (2009) 'The HADRIAN approach to accessible transport', Work, Vol. 33, No. 3, pp.335-344.

Marshall, R., Summerskill, S.J. and Cook, S. (2013) 'Development of a volumetric projection technique for the digital evaluation of field of view'. Ergonomics, Vol. 56, No. 9, pp.1437-1450.

Newell, A. F. and Gregor, P. (2000) 'User sensitive inclusive design - in search of a new paradigm', Proceedings on the 2000 conference on Universal Usability, ACM, pp.39-44.

New Scientist, 28 May 1970.

Porter, J.M., Case, K. and Bonney, M.C. (1990) 'Computer workspace modelling', in Wilson, J.R. and Coreltt, E.N. (Eds.), Evaluation of Human Work, pp.472-499, CRC Press: London.

Porter, J.M., Almeida, G.M., Freer, M.T. and Case, K. (1991) 'The design of supermarket workstations to reduce the incidence of musculoskeletal discomfort', in Queinnec, Y. et al (Eds.), Designing for Everyone and Everybody, Taylor \& Francis, London.

Porter, J.M., Case, K., Freer, M.T. and Bonney, M.C. (1993) 'Computeraided ergonomics design of automobiles', in Peacock, B. et al (Eds.) Automotive Ergonomics, Taylor \& Francis, London, pp.43-78.

Porter, J.M. (1994) Seating design: current problems and future strategies, Automotive Interiors International, pp.6-19, Turret Group plc.

Porter, J. M., Case, K. and Freer, M. T. (1996) 'SAMMIE computer aided ergonomics', Co-Design, the interdisciplinary journal of design and contextual studies, Vol. 7-8, pp.68-75.

Porter, J.M., Case, K. and Freer, M.T. (1999) 'Computer aided design and human models', in Karwowski, W. et al (Eds.), Handbook of Occupational Ergonomics, CRC Press LLC, Florida, pp.479-500. 


\section{Digital Human Modelling over Four Decades}

Porter, J.M. (2001) 'Beyond “Jack and Jill”: Designing for individuals within populations', Proceedings of the International Workshop on Anthropometrics of Disability, Buffalo, NY, USA. (http://design6.ap.buffalo.edu/rercud/publications.htm).

Porter, J.M. and Porter, C.S. (2001) 'Occupant accommodation: An ergonomics approach', in Happian-Smith, J. (Ed.), An Introduction to Modern Vehicle Design, Butterworth-Heineman, London, UK, pp.233276.

Porter J.M., Case, K., Gyi, D.E., Marshall, R. and Oliver R.E. (2002) 'How can we "design for all" if we do not know who is designed out and why?', Proceedings of the International Annual Occupational Ergonomics \& Safety Conference, Toronto, pp.1-6.

Porter, J. M., Marshall, R., Sims, R. E., Gyi, D. E. and Case, K. (2003) 'HADRIAN: a human modelling CAD tool to promote "design for all"', Proceedings of Inclusive Design for Society and Business, INCLUDE 2003, Vol. 6, pp.222-228. Royal College of Art, London, UK.

Porter, S., Case, K., Summerskill, S. J. and Marshall, R. (2009) 'Four decades of SAMMIE', In Ergonomics at 60: A Celebration, The Ergonomics Society, UK, pp.12.

Roebuck, J.A. Jnr., Kroemer, K.H.E. and Thomson, W.G. (1975) Engineering Anthropometry Methods, New York: John Wiley.

Ryan, P.W., Springer, W.E. and Hlastala, M.P. (1970) Cockpit geometry evaluation, Phase II. Final report. Vol. II - human data. Janair Report 700202.

Sheldon W.H. (1940) The Varieties of Human Physique, Harper \& Bros. New York.

Siemens (2015) NX 10, http://www.plm.automation.siemens.com/ (Accessed 30 November 2015).

Summerskill, S., Marshall, R. and Lenard, J. (2014) The design of category N3 vehicles for improved driver direct vision, Loughborough Design School. https://dspace.lboro.ac.uk/2134/15922 (Accessed 2 July 2015)

Stepney, P.O., Acar, B.S., Case, K. and Porter, J.M. (1996) 'Computer aided parametric solid modelling of the spine', Proceedings of Eurographics-UK. 


\section{Digital Human Modelling over Four Decades}

UNECE Regulation 46. (2015) Uniform Provisions for Devices for Indirect Vision and of Motor Vehicles with Regard to the Installation of these Devices, UN ECE Vehicle Regulations.

Von Gierke, H. E. (1971) 'Biodynamic models and their applications', Journal of the Acoustical Society of America, Vol. 50, pp.1397-1414.

Waterman, D. and Washburn, C.T. (1978) CYBERMAN - A human factors design tool, SAE Technical Paper 780283.

Yang, J., Marler, R. T., Kim, H. J., Farrell, K., Mathai, A., Beck, S., Abdel-Malek, K., Arora, J. S. and Nebel, K. (2005) 'Santos: a new generation of virtual humans’, SAE 2005 World Congress, April, Detroit, MI, Society of Automotive Engineers, Warrendale, PA. 